\title{
Insight into the Geothermal Structure in Chingshui, Ilan, Taiwan
}

\author{
Lun-Tao Tong ${ }^{1,}{ }^{*}$, Shoung Ouyang ${ }^{1}$, Tai-Rong Guo ${ }^{1,2}$, Ching-Ray Lee ${ }^{1}$, Kou-Hsin $\mathrm{Hu}^{1}$, \\ Chun-Li Lee ${ }^{3}$, and Chun-Jao Wang ${ }^{3}$ \\ ${ }^{1}$ Energy and Environment Research Laboratories, Industrial Technology Research Institute, Hsinchu, Taiwan, ROC \\ ${ }^{2}$ Institute of Geophysics, National Central University, Chung-Li, Taiwan, ROC \\ ${ }^{3}$ Bureau of Energy, Ministry of Economic Affairs, Taipei, Taiwan, ROC
}

Received 2 January 2007, accepted 30 August 2007

\begin{abstract}
The Chingshui geothermal field is the largest known productive geothermal area in Taiwan. The purpose of this paper is to delineate this geothermal structure by integrating geophysical data and borehole information. The existence of a magma chamber in the shallow crust and shallow intrusive igneous rock results in a high heat flow and geothermal gradient; furthermore, the NE deep fault system within the meta-sandstones provides meteoric recharge from a higher elevation to artesianally drive the geothermal system. There is evidence that geothermal fluid deeply circulated within the fracture zone and was heated by a deeply located body of hot rock. The geothermal reservoir of the Chingshui geothermal field might be related to the fracture zone of the Chingshuihsi fault. It is bounded by the C-fault in the north and Xiaonanao fault in the south. Based on information obtained from geophysical interpretations and well logs, a 3-D geothermal conceptual model is constructed in this study. Further, the geothermal reservoir is confined to an area that is $260 \mathrm{~m}$ in width, $\mathrm{N} 21^{\circ} \mathrm{W}, 1.5 \mathrm{~km}$ in length, and has an $80^{\circ}$ dip toward the NE. A high-temperature zone is found in the SE region of the reservoir, which is about $500 \mathrm{~m}$ in length; this zone is located near the intersection of the Chingshuihsi and Xiaonanao faults. An area on the NE side of the high-temperature zone has been recommended for the drilling of production wells for future geothermal development.
\end{abstract}

Key words: Chingshui geothermal field, Geothermal reservoir, Gravity, Magnetic, Magnetotellurics, Well log

Citation: Tong, L. T., S. Ouyang, T. R. Guo, C. R. Lee, K. H. Hu, C. L. Lee, and C. J. Wang, 2008: Insight into the geothermal structure in Chingshui, Ilan, Taiwan. Terr. Atmos. Ocean. Sci., 19, 413-424, doi: 10.3319/TAO.2008.19.4.413(T)

\section{INTRODUCTION}

Promotion of renewable energy sources is growing worldwide. Geothermal energy is one such energy source and it is both relatively cheap and efficient (Fridleifsson 2001; Bertani 2005; Lund et al. 2005). The Chingshui geothermal field is probably the most suitable area for generating geothermal energy in Taiwan as it is Taiwan's largest existing productive geothermal area (Lee 1994). A reconnaissance survey of this field was performed by the Industrial Technology Research Institute (ITRI) from 1973 to 1975 (Lee 1994). Further exploration was subsequently conducted by the Chinese Petroleum Corporation (CPC) from 1976 to 1980. Later, a geothermal power plant was built in this field by the National Science Council in 1981; however, the plant was decommissioned after 11 years.

* Corresponding author

E-mail: tong@itri.org.tw
During the exploitation stage, the ITRI and CPC conducted the following surveys: gravity (Lee 1994), resistivity (Cheng and Lee 1977; Su 1978), transient electromagnetic (Chiang and Liu 1983), and geologic (Tseng 1978; Hsiao and Chiang 1979). Nineteen deep production wells were drilled in a 6-km long band along the Chingshui stream, with commercially successful wells confined to a $2-\mathrm{km}^{2}$ area at the $\mathrm{SE}$ end of this zone. The highest temperatures measured ranged between $200^{\circ} \mathrm{C}$ and $220^{\circ} \mathrm{C}$ (Lee 1994).

Although some exploration of this field has been undertaken in the past (Cheng and Lee 1977; Su 1978; Tseng 1978; Hsiao and Chiang 1979; Chiang and Liu 1983; Lee 1994), the structure of the geothermal reservoir is still not well delineated; this could affect the design of new production wells as regards their appropriate locations and borehole traces. This study aims to delineate the geothermal structure of this field by integrating geophysical data and 
borehole information. For this, geomagnetic and gravity datasets acquired in the Ilan plain and the Chingshui area were reprocessed and interpreted. Furthermore, additional magnetotelluric (MT) data acquired in this study and well information were integrated to establish the geothermal conceptual model for the Chingshui area.

\section{HISTORICAL AND GEOLOGIC BACKGROUND}

Taiwan constitutes a complex collision zone between the Eurasian and Philippine tectonic plates. In the southern part of Taiwan, the Eurasian Plate is being subducted beneath the Philippine Plate, forming the northernmost part of the Luzon arc. This subduction zone is terminated by the collision of the Philippine Plate with the continental crustal part of the Eurasian Plate north of the Luzon arc. Part of the Eurasian Plate continental crust was initially subducted; however, when the subduction ceased, it became buoyant and experienced strong uplift and erosion. This led to the formation of Taiwan's Central Range, resulting in high heat flow (Lin 2000). This uplift and erosion started in northern Taiwan and then propagated southward. In the north, the Philippine Plate is being subducted beneath the Eurasian Plate, leading to the formation of the Ryukyu arc. However, on the west of the Ryukyu arc, the continental crust portion of the Eurasian Plate has collided with and terminated this part of the subduction zone. Some magma chambers remain in the shallow crust. They have produced northern Taiwan's most recent volcanism (Lin and Yeh 2001; Chen et al. 2002; Lin et al. 2004) and provide the heat source of the Chingshui geothermal field (Yu and Tsai 1979; Lin and Yeh 2001).

The Slate Belt and Schist Belt in NE Taiwan can be distinguished into four blocks based on structural analysis and stratigraphy (Lin and Yang 1999) - the Minchih Block, the Taipingshan Block, the Suao Block, and the Nanao Block. The Chingshui geothermal field is located in the Taipingshan Block, which is bounded by the Niutou fault in the west and the Kulu fault in the east (Fig. 1). The reverse-slip faults and normal faults in the Taipingshan Block were formed after the Penlai Orogeny since the Late Pliocene in phases 6 and 7 (Lin and Yang 1999).

As shown in Fig. 1, the Chingshui geothermal field is located in the valley of the Chingshui stream, in northeastern Taiwan, about $27 \mathrm{~km} \mathrm{SW}$ of Ilan. It is located at the northeastern end of the submetamorphic zone of Taiwan. The rocks hosting the geothermal field are likely to be of prehnite-pumpellyite metamorphic facies (Tseng 1978; Lin and Lin 1995). They are meta-sandstones and intercalated slates of the Jentse Member of the Miocene Lushan Formation (Chiang et al. 1979; Hsiao and Chiang 1979). They

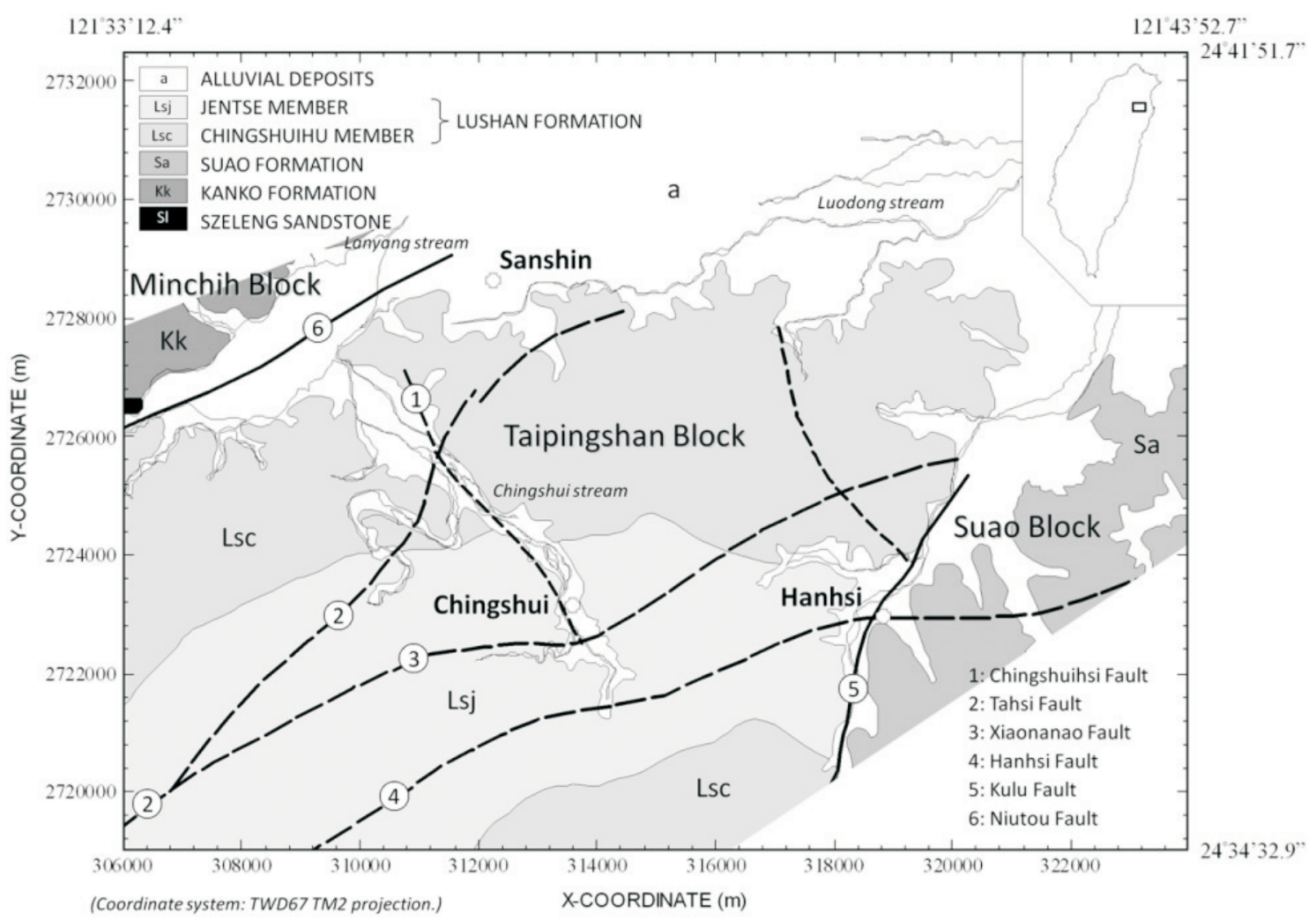

Fig. 1. Generalized geological map of the Chingshui area. Chingshui is located in the Taipingshan Block, and the host rock in the geothermal field is the Jentse Member of the Lushan Formation. The dominant fault system in the Taipingshan Block lies along a NE direction, whereas the NW is characterized by dextral strike slipping; here the steeply dipping Chingshuihsi fault is most prominent. 
comprise quartz, albite, illite, and chlorite (Yui et al. 1993). This member is underlain by slates of the Chingshuihu Member of the Lushan Formation in the NW and SE, and it is in thrust fault contact with the meta-sandstones and slates of the Suao Formation in the east.

In the middle area of Fig. 1, the competent meta-sandstones lie within a monocline in which fracture and deformation predominate. The more slate-rich formations are in folds. Dips in the Jentse Member in this area are steep to the SE. A set of faults and fractures orthogonally cut the sequence and dip at $65^{\circ}$ to $80^{\circ}$ to the NE (Tseng 1978). Lin and Lin (1995) proposed that the Chingshui geothermal field might be controlled by the Chingshuihsi fault. However, no obvious outcrops of this fault can be found on the surface.

\section{GEOMAGNETIC SURVEY IN THE ILAN PLAIN}

A geomagnetic survey in the Ilan plain was performed in 1978 by Yu and Tsai (1979). Data from a total of 425 stations were acquired. This dataset has been reprocessed in this study to analyze possible heat sources and fluid channels of the Chingshui geothermal field. A 300-m total magnetic intensity (TMI) grid is created. Figure 2 shows magnetic anomaly maps of the Ilan plain. An obvious WE high magnetic anomaly located between Ilan and Luodong can be easily observed (Fig. 2b). Yu and Tsai (1979) interpreted that this anomaly represents the igneous rocks of the Ryukyu arc at depth and in turn may indicate the deep heat source for the geothermal activity of the Chingshui area. As shown in Fig. 2b, a low magnetic zone between Chingshui and Hanhsi can be observed, which might be associated with the destruction of magnetite in the host rocks by hydrothermal alteration.

Euler deconvolution is widely used to estimate the apparent depth to a magnetic source (Reid et al. 1990; Hsu 2002; Salem and Ravat 2003). This process relates a magnetic field and its gradient components to the location of the source of an anomaly, with the degree of homogeneity expressed as a "structural index." Euler's homogeneity relationship for magnetic data can be written in the following form:

$$
\left(x-x_{0}\right) \frac{\delta T}{\delta x}+\left(y-y_{0}\right) \frac{\delta T}{\delta y}\left(z-z_{0}\right) \frac{\delta T}{\delta z}=N(B-T)
$$

where $\left(x_{0}, y_{0}, z_{0}\right)$ is the position of a magnetic source whose total field $(T)$ is detected at $(x, y, z) . B$ is the regional magnetic field. $N$ is the measure of the fall-off rate of the magnetic field, and it may be interpreted as the structural index (SI). The source positions for a particular SI can be obtained by inverting equation 1 over a window of data at every grid point. A 50-m upward continuation is applied to the total magnetic field (Fig. 2a) in order to attenuate noise without changing the physical significance of the data. A $4.5-\mathrm{km}$ square-window is used to calculate the
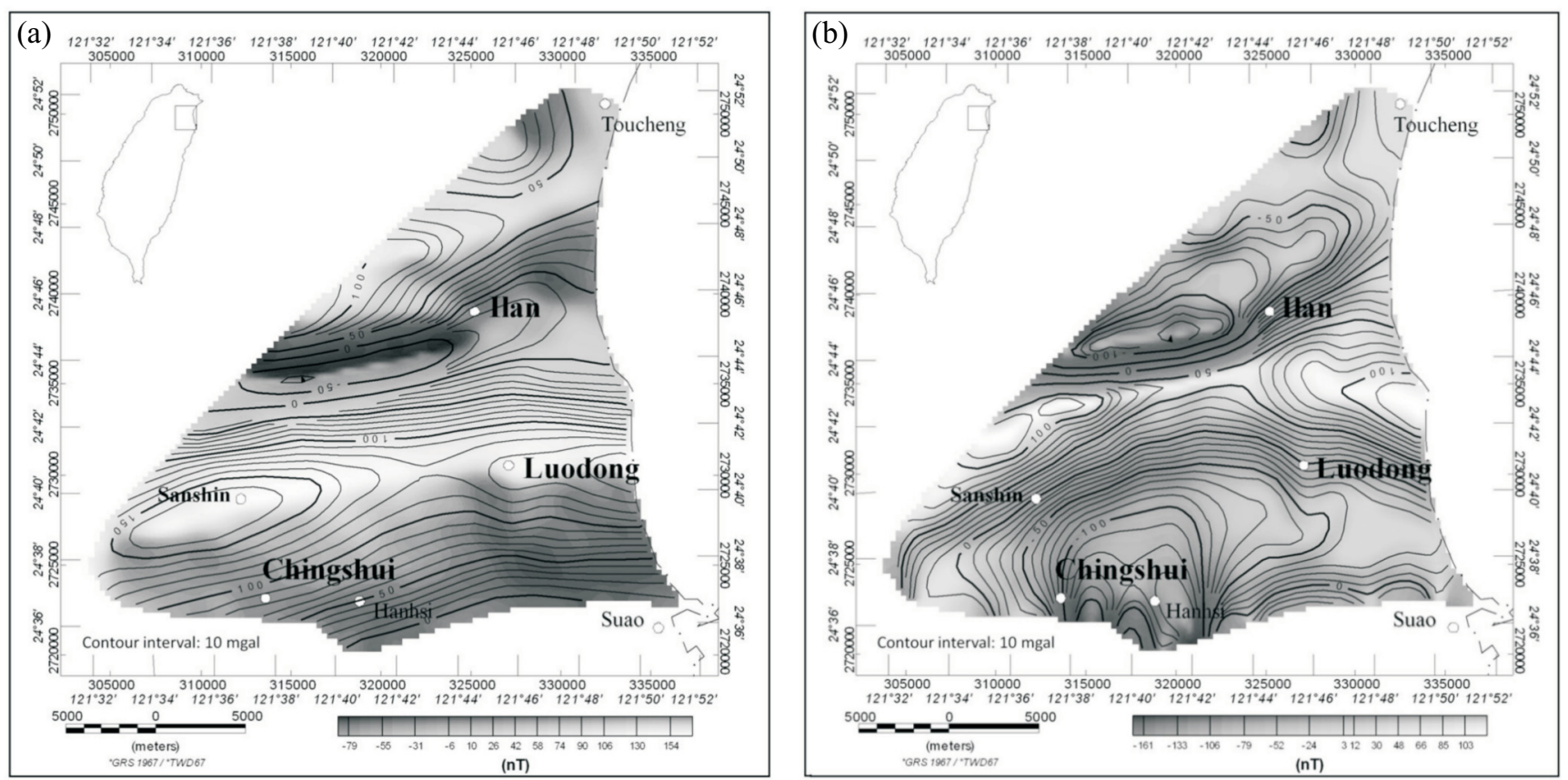

Fig. 2. Magnetic anomaly contour map of the Ilan plain. (a) Total-field magnetic anomaly produced after International Geomagnetic Reference Field (IGRF) correction. (b) Magnetic anomaly produced after IGRF correction and reduction to the pole. An obvious WE high magnetic anomaly extending from the eastern coastline to the western edge of the Ilan plain can be observed; this anomaly might be associated with igneous intrusive rock (Yu and Tsai 1979). 
Euler solutions. To identify good solutions for the location and attributes of a structure, depth, and location uncertainties should be restricted to a reasonable range. Furthermore, good solutions should be clustered with the corresponding structure index, which could be manually selected. A total of 2171 and 3464 solutions are obtained with a $15 \%$ maximum depth tolerance for fault $(\mathrm{SI}=0)$ and dyke ( $\mathrm{SI}=1)$, respectively. The offset between the location of the solution and the center of the operating window along the $X$ and $Y$ directions are restricted between -4.5 and $4.5 \mathrm{~km}$ to window the solution prior to creating the final solution list.

Figure 3 shows the surface projection of the fault and dyke solutions in the Ilan plain, and Fig. 4 shows its 3-D view beneath the Ilan plain. Three groups of dyke solutions can be identified, as shown in Fig. 3a, and they are labeled as DA, DB, and DC. No dyke solution can be found in the southern region of the Ilan plain. The shaded area clustered with DB and DC (Figs. 3a, 4) could be related to the WE high magnetic anomaly shown in Fig. $2 b$ that was interpreted by Yu and Tsai (1979) as a thick dyke, approximately $4.7-7 \mathrm{~km}$ in width, located between Ilan and Luodong. As shown in Fig. 3b, three groups of fault solutions can be observed and are labeled as FA, FB, and FC; they have the same NE trends as those proposed by Hsu et al. (1996) from the macro point of view. The depths of FA and FB may be shallower than $2 \mathrm{~km}$. FC has a greater depth, down to more than $3 \mathrm{~km}$, and extends from the south of Luodong to Chingshui.
Based on the $V_{P}$ and $V_{S}$ velocity structures and $V_{P} / V_{S}$ ratios, a sausage-like body with a low $V_{S}$ and high $V_{P} / V_{S}$ ratio, approximately $30 \mathrm{~km}$ in diameter, was found at depths ranging between 20 and $100 \mathrm{~km}$ (Lin et al. 2004; their Fig. 10). This might be associated with a partially molten magma body (Lin et al. 2004). The magma propagates upward within the upper brittle crust through veins and/or narrow conduits (Lin et al. 2004). Therefore, it is possible that the upper part of the upward magma body has cooled to below its Curie temperature to appear as the high magnetic anomaly shown in Fig. 2. As shown in Figs. 3 and 4, we propose that the existence of the magma chamber in the shallow crust and the intrusive igneous rock results in a high heat flow and geothermal gradient, and the NE deep fault system within the meta-sandstones provides meteoric recharge from a higher elevation to artesianally drive the geothermal system. The ${ }^{3} \mathrm{He} /{ }^{4} \mathrm{He}$ ratio of the gas samples collected in the Chingshui geothermal field shows significant mantle input, $14 \%$ to $19 \%$, and implies that mantle fluids may have invaded the Chingshui geothermal field (Yang et al. 2005). This confirms that the geothermal fluid had deeply circulated within the fracture system and was heated by a deep hot body of rock.

\section{GRAVITY SURVEY IN CHINGSHUI AREA}

A gravity survey in the Chingshui area was completed by the ITRI in 1976 (Lee 1994), and data from a total of 636 stations were acquired. This dataset has been reprocessed to
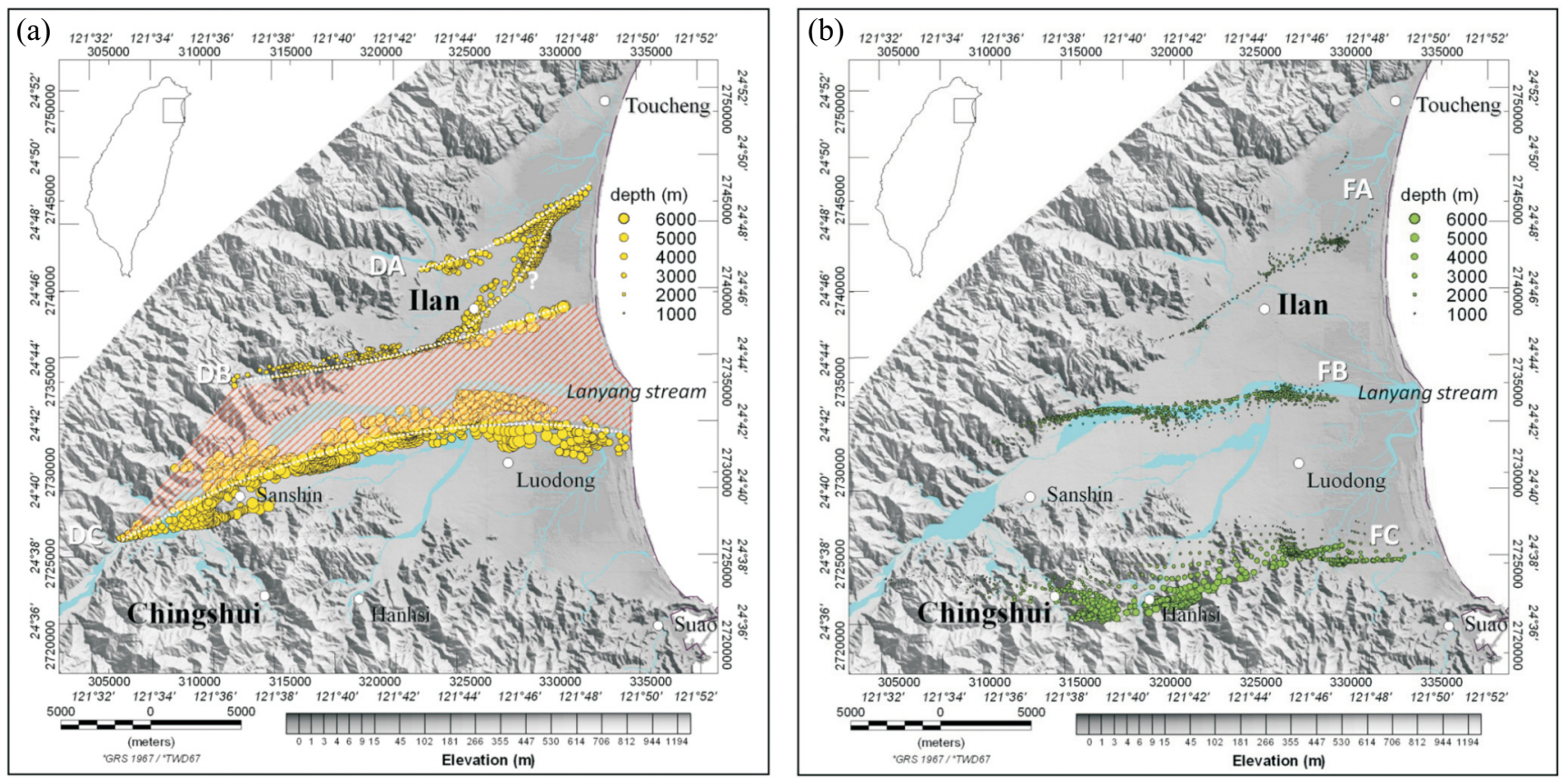

Fig. 3. Distribution of fault and dyke solutions based on the Euler deconvolution of the total magnetic field. The shaded-relief topography map is used as a base map. (a) Dyke solutions - three groups of dykes can be recognized. (b) Fault solutions - three groups of faults can be recognized. The shaded area clustered with DB and DC could be related to the WE high magnetic anomaly shown in Fig. 2 b. 


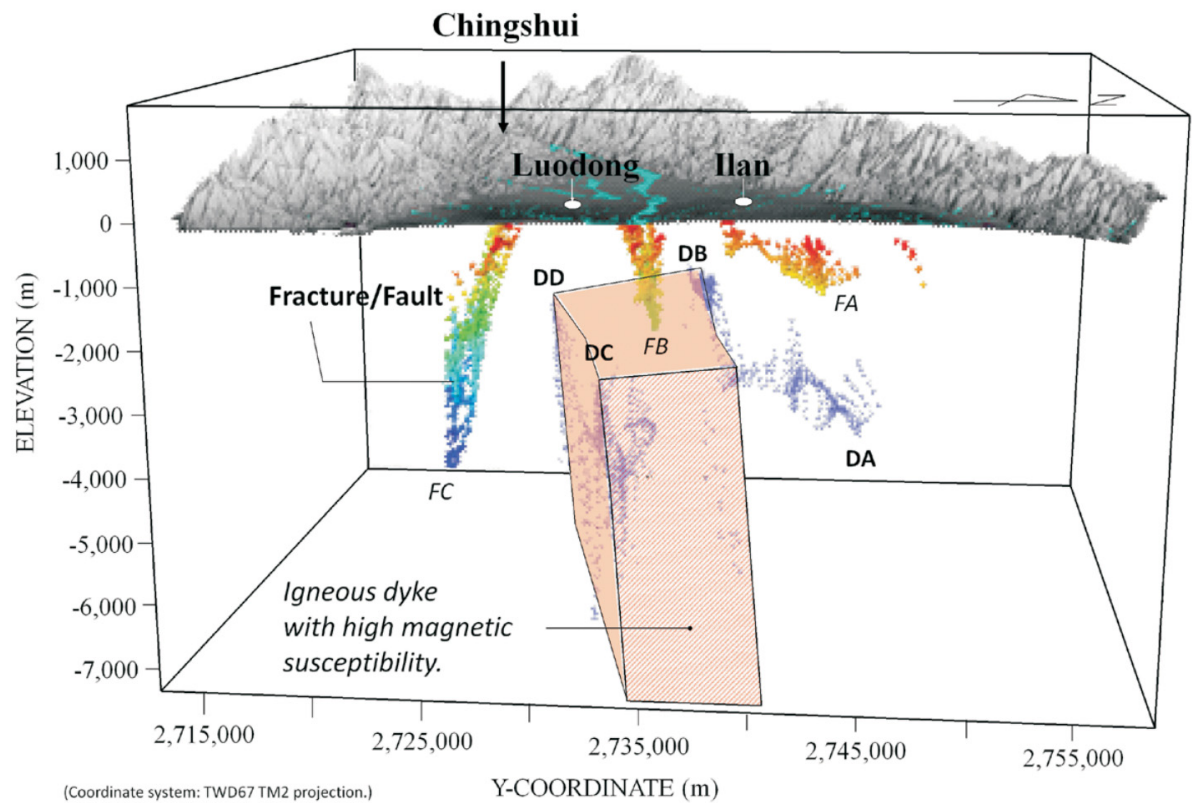

Fig. 4. A 3-D view of fault and dyke solutions (Fig. 3) beneath the Ilan plain. The shaded area clustered with DB and DC is coincident with the WE high magnetic anomaly shown in Fig. $2 b$ that could be related to a thick dyke of high magnetic susceptibility. The existence of the shallow intrusive igneous rock might result in a high geothermal gradient to heat the geothermal fluid circulated within the deep fractures.

analyze fault structures in the vicinity of Chingshui. A 200-m spacing Bouguer gravity grid (Fig. 5) is created after full terrain correction (Tong and Guo 2007). Figure 6 shows the residual gravity anomaly map after third-order trend removal. The change in gravity is not large in this range due to the fact that the formation in the survey area is mainly slate. However, from the gravity maps (Figs. 5, 6) it is apparent that the gravity on both sides of the Chingshui stream is dif- ferent and could be related to fault activities.

Euler deconvolution is used for rapid interpretation of gravity data. It is particularly good at delineating contacts and rapid depth estimation (Keating 1998; Roy et al. 2000). Before apply Euler deconvolution to the gravity data, a $500-\mathrm{m}$ upward continuation is applied to the Bouguer gravity grid (Fig. 5) to attenuate considerable noise and to represent the characteristics of the deeper structure. A $600-\mathrm{m}$

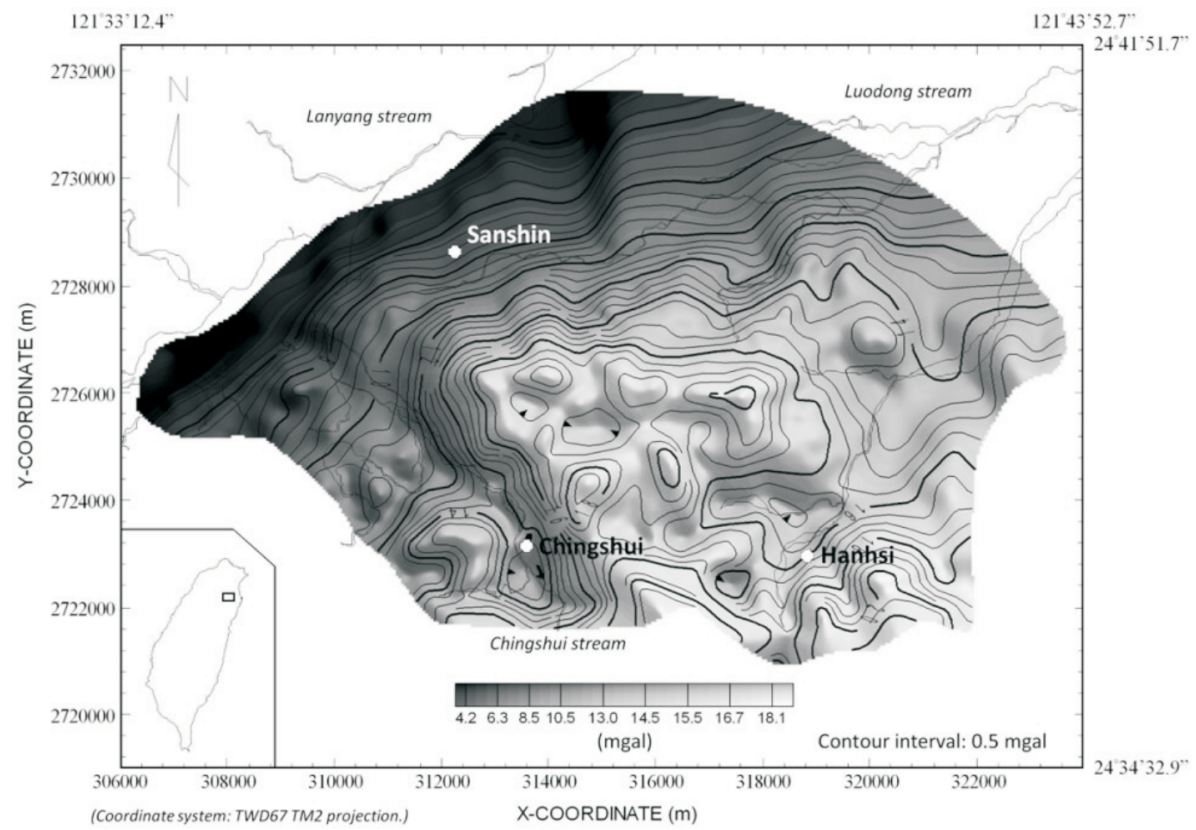

Fig. 5. The shaded-relief Bouguer gravity map of the Chingshui area. The gravity on either side of the Chingshui stream is different and could be related to the fault activities. 


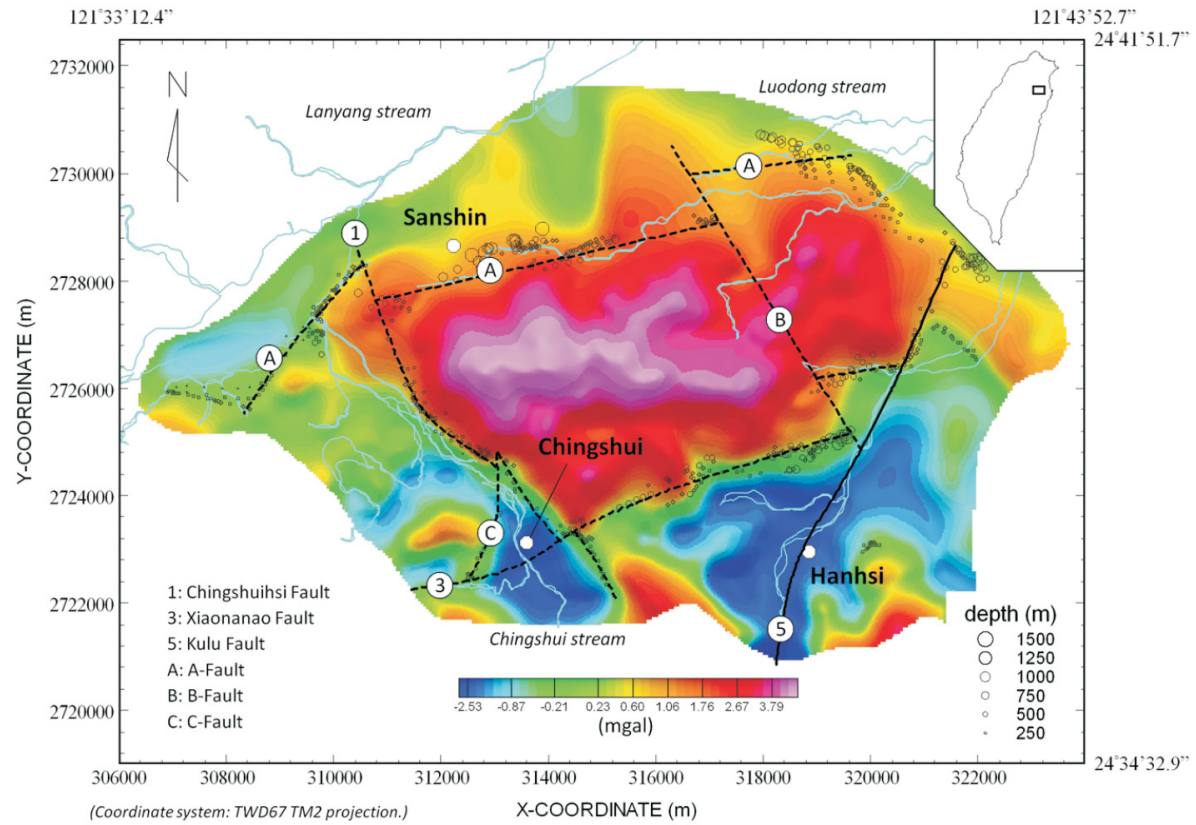

Fig. 6. Color shaded-relief residual gravity map of the Chingshui area. The circle represents the fault solutions based on Euler deconvolution. Based on quantitative analysis together with knowledge of the adjacent geology, six faults are identified. Among them, the Xiaonanao, Chingshuihsi, and Kulu faults correspond well with the known faults.

square window is used to calculate the Euler solutions for a fault $(\mathrm{SI}=0)$. A total of 931 solutions are obtained with a $10 \%$ maximum depth tolerance. In order to at least eliminate the worst cases, the location uncertainty is restricted to below $50 \%$ prior to creating the final solution list. Figure 6 shows the distribution of the fault solutions, which are superposed on the residual gravity map for interpretation.

Based on the results of Euler deconvolution together with known adjacent geology, six faults are interpreted and labeled in Fig. 6. Among these faults, the Xiaonanao, Chingshuihsi, and Kulu faults correspond with known faults introduced by Tseng (1978) and Lin and Yang (1999). The A-fault, which might be associated with the Niutou fault (Fig. 1), has a SW-NE trend and was offset by the B-fault and the Chingshuihsi fault. As shown in Fig. 6, the Chingshuihsi fault offsets the A-fault, indicating a dextral fault, and shows a NW-SE extension along the Chingshui stream. The Chingshuihsi fault might also have a vertical component due to both the value and features of the gravity anomaly on both its sides being different (Fig. 6). The Chingshuihsi fault was offset by the Xiaonanao fault and the C-fault in the south and north of Chingshui, respectively, and the known geothermal field in this region is bounded by the $\mathrm{C}$-fault and the Xiaonanao fault. The Kulu fault, when it was formed, separated the Taipingshan Block from the original Suao Block (Lin and Yang 1999).

\section{MAGNETOTELLURIC SURVEY IN THE CHINGSHUI AREA}

The magnetotelluric (MT) survey method has been suc- cessfully used for exploring geothermal reservoirs (Uchida et al. 2005; Ushijima et al. 2005; Wannamaker et al. 2005). It is believed that geothermal fluid circulates in the fractures within the meta-sandstones in the Chingshui geothermal field (Tseng 1978; Hsiao and Chiang 1979). To delineate the structure of the geothermal reservoir in the Chingshui area, 33 broadband magnetotelluric data points were acquired by the ITRI in June 2006. Figure 7 shows the location map of the MT stations. MTU-5 (Phoenix Geophysics, Toronto, Canada) was used to record the MT signals. Two orthogonal components of the horizontal electric field and three components of the magnetic fields induced by natural primary sources were measured simultaneously as a function of frequency. The magnetic field was determined using a high-sensitivity coil with built-in preamplifiers. The electric field was determined by measuring the voltage differences taken over a nominal bipolar span of $50 \mathrm{~m}$. The contact endpoints of the bipoles were porous pot electrodes placed in holes about $30-\mathrm{cm}$ deep in which bentonite mixed with water was added to improve contact. Recording time for each station was more than $72 \mathrm{~h}$ in order to improve the quality of data.

A polar plot represents the variation of the surface impedance $\left(Z_{x y}\right)$ as different rotations were applied to the impedance tensor. It allows one to quickly understand the electrical homogeneity of the ground in the survey area. Figure 8 shows the polar diagram of $Z_{x y}$ for each station at $10 \mathrm{~Hz}$. The polar diagrams show that most of the polarization is along the NW-SE direction, which could be related to the major direction of the fault/fracture structure in the vi- 


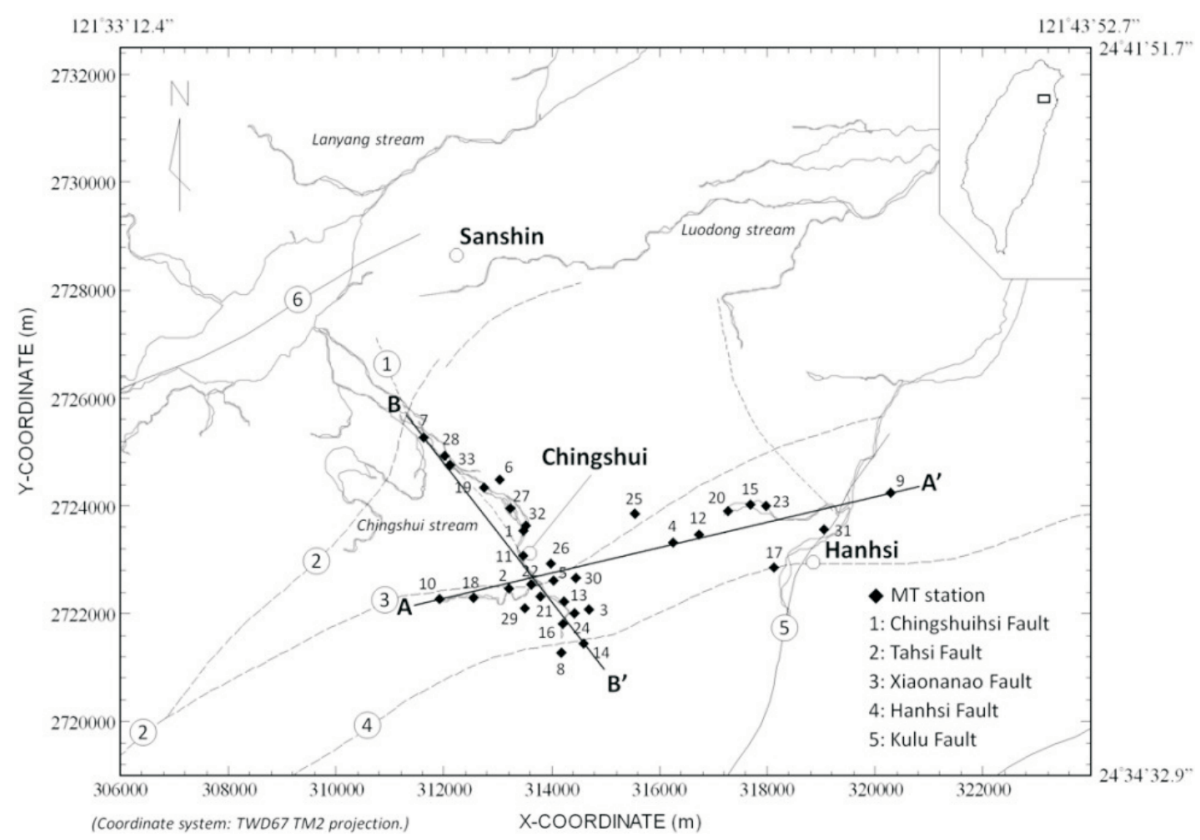

Fig. 7. MT stations in the Chingshui area. Most of the stations are restricted to the valley due to the rugged topography.

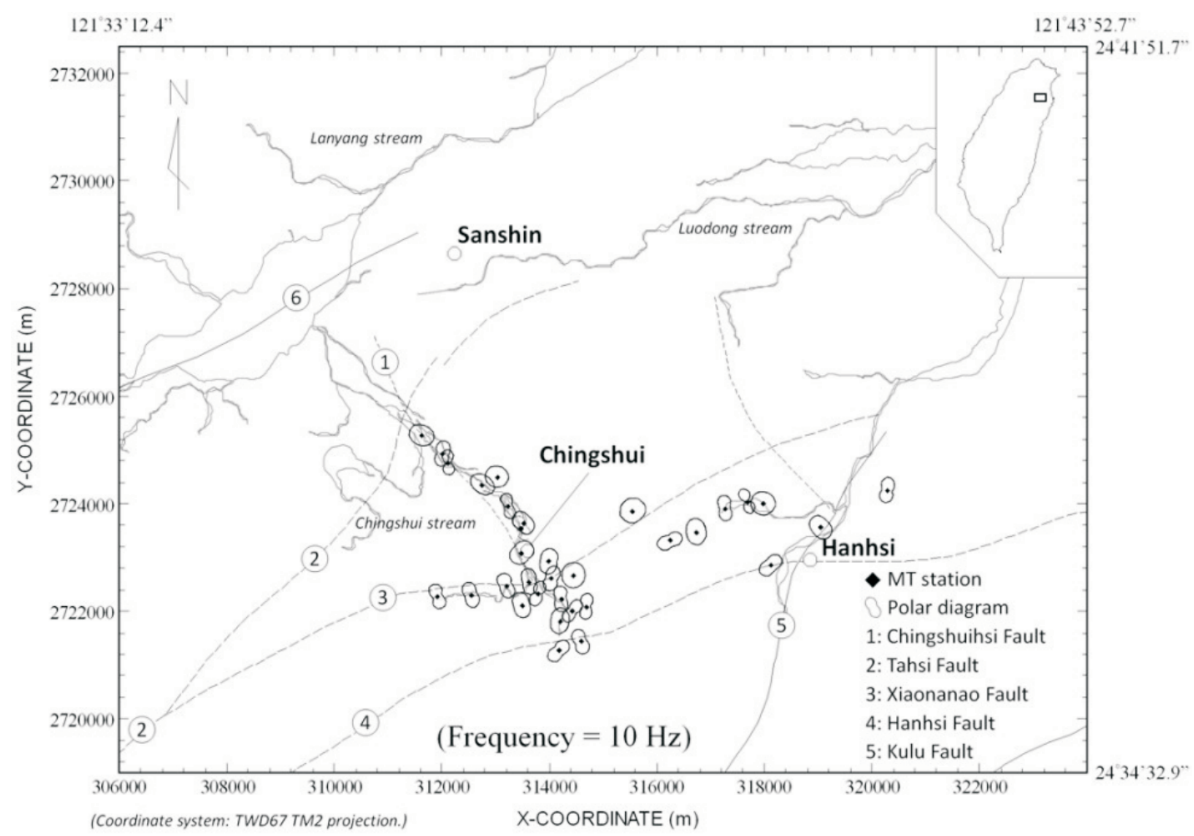

Fig. 8. Polar diagram of the MT stations at $10 \mathrm{~Hz}$ in the Chingshui area. Most of the polarization is in the NW-SE direction, which could be related to the major direction of the fault/fracture structure in the vicinity of Chingshui.

cinity of Chingshui. Thus, the Chingshuihsi fault should be the major structure that influences the flow of telluric current in this area.

Where the geological structure is complicated, a 1-D inversion of the MT data may produce an error due to lateral variation. 2-D inversion has been widely used to interpret MT data; it provides a more objective interpretation and is less time-consuming than the trial-and-error approach. A common approach to fit a 2-D MT dataset is to construct a cross section of the area based on prior geologic knowledge and model parameterization to solve for conductivities by least-square inversion. In this paper, the 2-D inversion algorithm proposed by Rodi and Mackie (2001), which is a nonlinear conjugate gradient (NLCG) algorithm, is used to construct the resistivity image of the desired transverse. The NLCG scheme minimizes an objective function containing data residuals and the second spatial derivatives of resistivity. Inversions were carried out by using both TE and TM data. 
A reasonable interpretation of the MT data could be achieved based on the understanding of the resistivity of various types of rocks in the survey area. Figure 9 shows rock resistivities measured on the outcrops in the vicinity of Chingshui. The resistivity of the host rock ranged from 167 to $537 \Omega \mathrm{m}$. However, the resistivity measured on the outcrop of the thermal alternative zone is $20 \Omega \mathrm{m}$, which is significantly different from the resistivity of the host rock. Figure 10 shows the 2-D resistivity sections of profiles A and B (Fig. 7), which best fit the measured data after 2-D inversion; the normalized root mean square (RMS) values are 8.79 and $12.91 \Omega \mathrm{m}$, respectively. A significant low-resis-

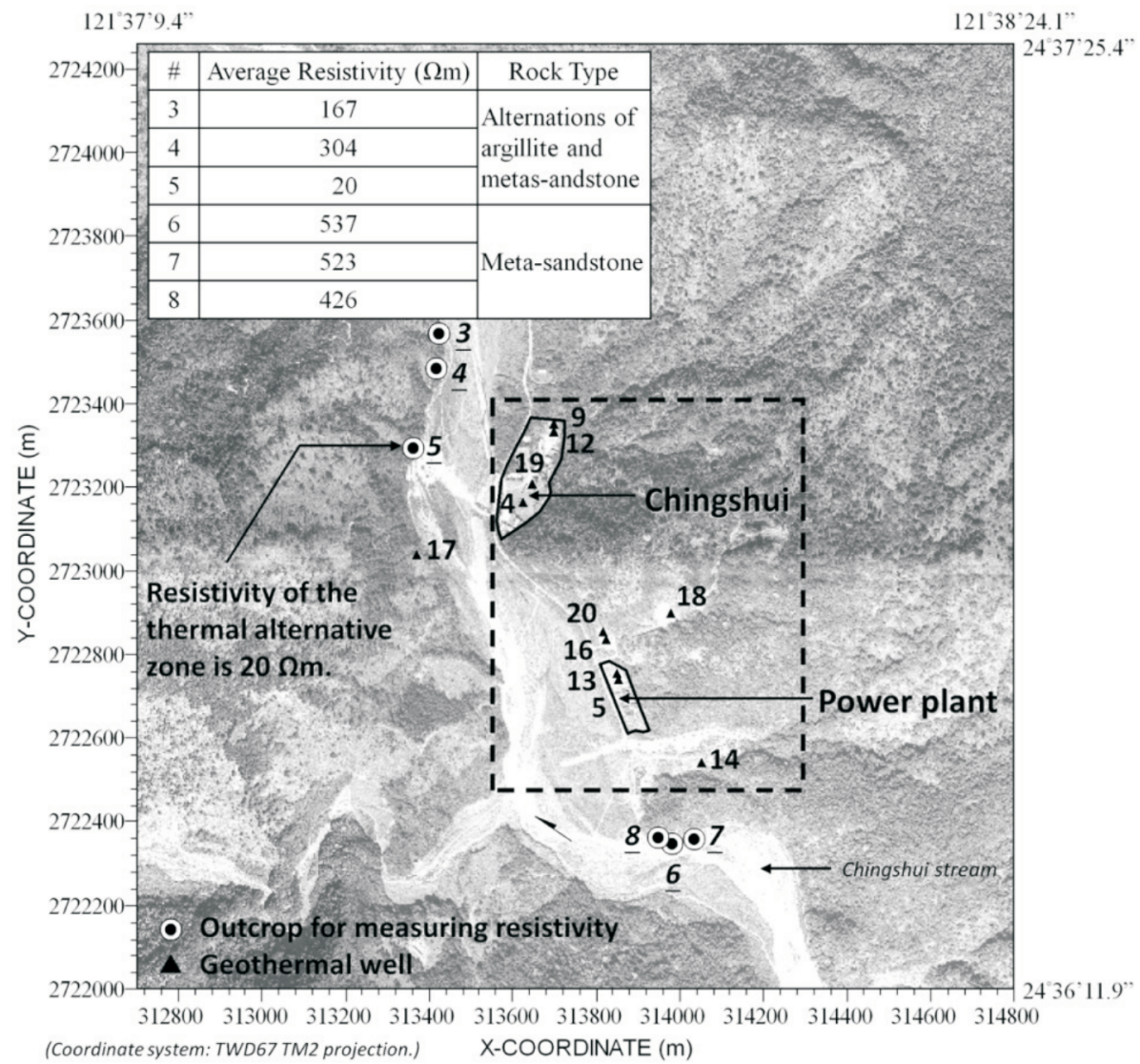

Fig. 9. Production wells in the Chingshui geothermal field. The aerial photo is used as a base map. Among these, wells 17 and 18 are nonproductive. The formation resistivities measured from the outcrops are also listed in this figure. The resistivity of the thermal alternative zone is $20 \Omega \mathrm{m}$, which is much lower than the resistivity of the host rock. The dashed box is used for demonstrating the 3-D view of the geothermal conceptual model shown in Fig. 12.

(a)

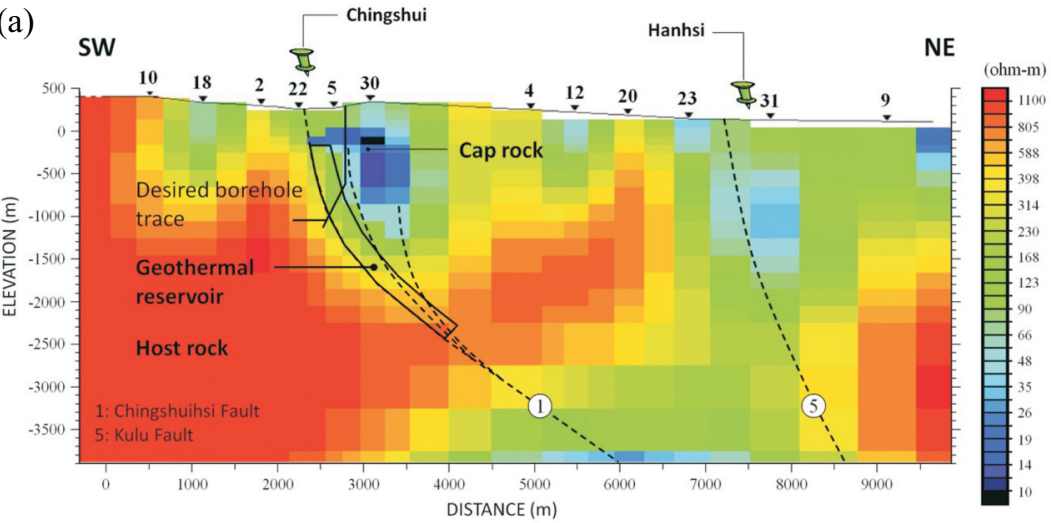

(b)

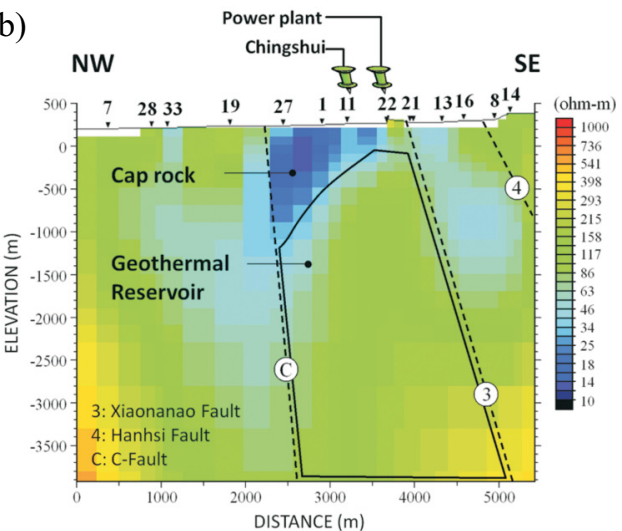

Fig. 10. Resistivity section of (a) profile A and (b) profile B. The cap rock can be identified as the low-resistivity zone lying on top of the reservoir. The desired borehole trace should be drilled vertically downward to a certain depth and then directed toward the reservoir to penetrate all possible feed zones within the reservoir. 
tivity zone can be identified in Figs. 10a and b; this zone could be related to a clay-rich cap rock in the geothermal structure. The cap rock shown in Fig. 10a is about $1 \mathrm{~km}$ in width and is found at depths ranging between 0.2 and $1 \mathrm{~km}$. The resistivity of the cap rock is about $14 \Omega \mathrm{m}$, which is not as low as that of many other geothermal fields that typically have a low-resistivity cap layer of less than $5 \Omega \mathrm{m}$. This may be a consequence of the Chingshui geothermal field having meta-sedimentary host rocks that are expected to be less reactive than the volcanic rocks of other fields. This would confirm the observation of Yui et al. (1993) that argillites and slates from within the field remain unaltered.

The fracture zone of the Chingshuihsi fault can be interpreted to be an indication of lateral resistivity discontinuity, and its dip-angle changes from steep at shallow depths to gentle at deep depths (Fig. 10a). The cap rock of the geothermal structure was formed on top of the geothermal fluid channels. As shown in Fig. 10a, the width of the fracture zone of the Chingshuihsi fault might change from narrow at deep depths to wide at shallow depths, and this feature might be associated with the flower structure of the strike-slip fault (Fig. 10a). As shown in Fig. 10b, the geothermal reservoir, approximately $1.5 \mathrm{~km}$ in length and dipping toward the north, is bounded by the $\mathrm{C}$-fault in the north and the Xiaonanao fault in the south.

\section{GEOTHERMAL CONCEPTUAL MODEL OF CHINGSHUI GEOTHERMAL FIELD}

Based on quantitative analysis of the geophysical data together with knowledge of the geology in the Chingshui area, Fig. 11 shows a 3-D view of the fault systems in the vicinity of Chingshui. The geothermal reservoir, with a NW-SE trend and about $1.5 \mathrm{~km}$ in length, might be associated with the fracture zone of the Chingshuihsi fault and is bounded by the $\mathrm{C}$-fault and the Xiaonanao fault in the north and south, respectively.

Nineteen deep production wells were drilled by the CPC in the past, and an additional 500-m borehole was drilled in 2006 by the ITRI. The well logs collected from 11 boreholes (Table 1) are used to analyze the spatial structure of the geo-

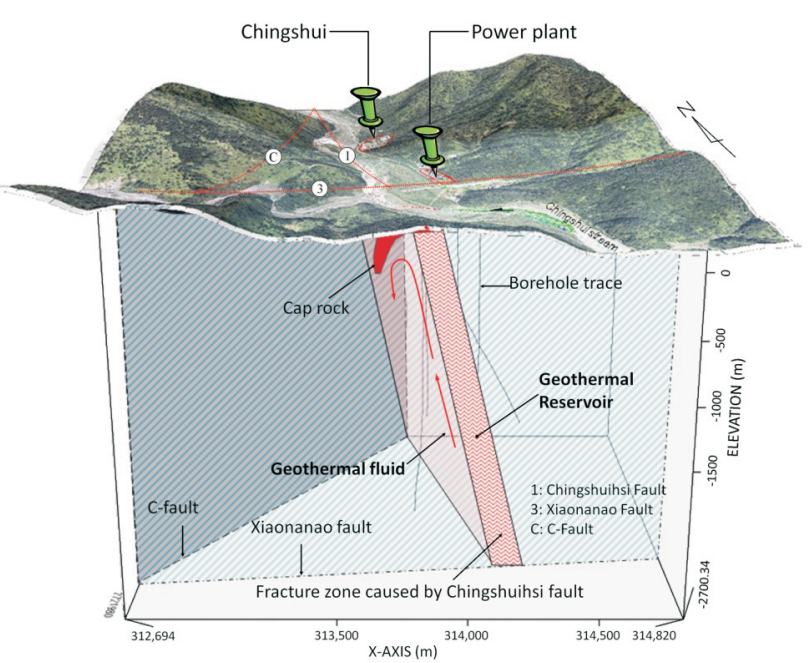

Fig. 11. The geothermal conceptual model of the Chingshui area. The geothermal reservoir might be associated with the fracture zone of the Chingshuihsi fault, and it is bounded by the $\mathrm{C}$-fault and the Xiaonanao fault in the north and south, respectively.

Table 1. Basic information on the production wells used in this study. Wells 9 and 18 were drilled twice at the same position. Well 9-2 was abandoned due to material accumulation in the hole. Wells 17, 18-1, and 18-2 were abandoned as they were nonproductive.

\begin{tabular}{ccccccc}
\hline Well No. & $\begin{array}{c}\text { Completion } \\
\text { date }\end{array}$ & $\begin{array}{c}\text { Well head } \\
\text { elevation (masl) }\end{array}$ & Hole depth (m) & $\begin{array}{c}\text { Max. temp } \\
\left({ }^{\circ} \mathbf{C}\right)\end{array}$ & $\begin{array}{c}\text { Max. productivity } \\
(\mathbf{t} / \mathbf{h})\end{array}$ & $\begin{array}{c}\text { Production casing } \\
\text { range (m) }\end{array}$ \\
\hline 4 & 1976 & 252.5 & 1505 & 201 & 114.3 & $539-1505$ \\
5 & 1977 & 269.4 & 2005 & 220 & 61.3 & $495-1998$ \\
$9-1$ & 1977 & 260.3 & 2074 & 205 & 68.4 & $490-2074$ \\
$9-2$ & 1977 & 260.3 & 2086 & - & - & $508-2081$ \\
12 & 1977 & 260.7 & 2000 & 223 & 31.7 & $1048-1998$ \\
13 & 1977 & 269.5 & 2020 & 219 & 76.8 & $505-2015$ \\
14 & 1978 & 281.5 & 2003 & 215 & 42.8 & $947-2003$ \\
16 & 1979 & 272.6 & 3000 & 225 & $30-128$ & $833-2993$ \\
17 & 1981 & 266.7 & 1848 & 167 & - & $1067-1831$ \\
$18-1$ & 1982 & 294.8 & 2450 & 239 & - & $769-449$ \\
$18-2$ & 1982 & 294.8 & 2231 & 215 & - & - \\
19 & 1986 & 257.7 & 901 & 206 & 48 & $159-896$ \\
20 & 2006 & 272.6 & 500 & 170 & 30 & $200-500$ \\
\hline
\end{tabular}


thermal reservoir in detail. Figure 12 a shows the $3-\mathrm{D}$ borehole traces and the feed zones of each borehole. Wells 17 and 18 have high temperatures, but insufficient quantity of hot water and no obvious feed zones; this implies that these two wells do not penetrate the feed zone in the geothermal reservoir. Thus, the geothermal reservoir is clustered with feed zones, which are confined in an area $260 \mathrm{~m}$ in width, $\mathrm{N} 21^{\circ} \mathrm{W}$, and $\operatorname{dip} 80^{\circ}$ to the NE (Fig. 12a). This is in agreement with the results of MT and gravity interpretation.

For visualizing the temperature of the geothermal reservoir, a 3-D grid was constructed using 24-h logging data obtained from the temperature recovery test conducted on 11 boreholes. As shown in Fig. 12b, the iso-temperature surface dips steeply toward the east, coinciding with the dipping fracture zone of the Chingshuihsi fault (Fig. 10a). The hightemperature hot water rises upward in the SE region of the geothermal reservoir, which is located near the intersection of the Chingshuihsi and Xiaonanao faults. Thus, the Xiaonanao fault might play an important role in the evolution of the Chingshui geothermal field. In this high-temperature zone, approximately $500 \mathrm{~m}$ in length, the temperature of the geothermal fluid can reach $140^{\circ} \mathrm{C}$ and $160^{\circ} \mathrm{C}$ at depths of 200 and $600 \mathrm{~m}$, respectively.

Figure 13 shows the surface projection of borehole traces and the geothermal reservoir. It appears that all the productive wells drilled in the past are located inside the fracture zone (Fig. 13), and the borehole traces also lie within the fracture zone (Fig. 12). Because the geothermal reservoir dips to the NE, the most suitable location for drilling production wells should be on the NE side of the reservoir, as shown in Fig. 10a. The design of a borehole trace should be separated into two parts - vertical and directional drilling (Fig. 10a). In other words, the trace should first be drilled vertically downward up to a certain depth and then directed toward the reservoir so as to penetrate all possible feed zones within the reservoir. The shaded areas halfway up the hill, labeled as A and B in Fig. 13, are the candidate areas for drilling production wells in the future for geothermal development. The main advantage of drilling wells in the proposed area is the reduction in drilling risk and pressure loss from the production well to the turbine. Area A, which lies beside the high-temperature zone, is the most suitable area for drilling production wells in the future since the recommended depth in this area is $1500 \mathrm{~m}$. On the other hand, the recommended depth of a well in area B is greater than $2000 \mathrm{~m}$ owing to the greater depth of the reservoir in this area (Fig. 10b).

\section{CONCLUSIONS}

Based on quantitative analysis of the geomagnetic data

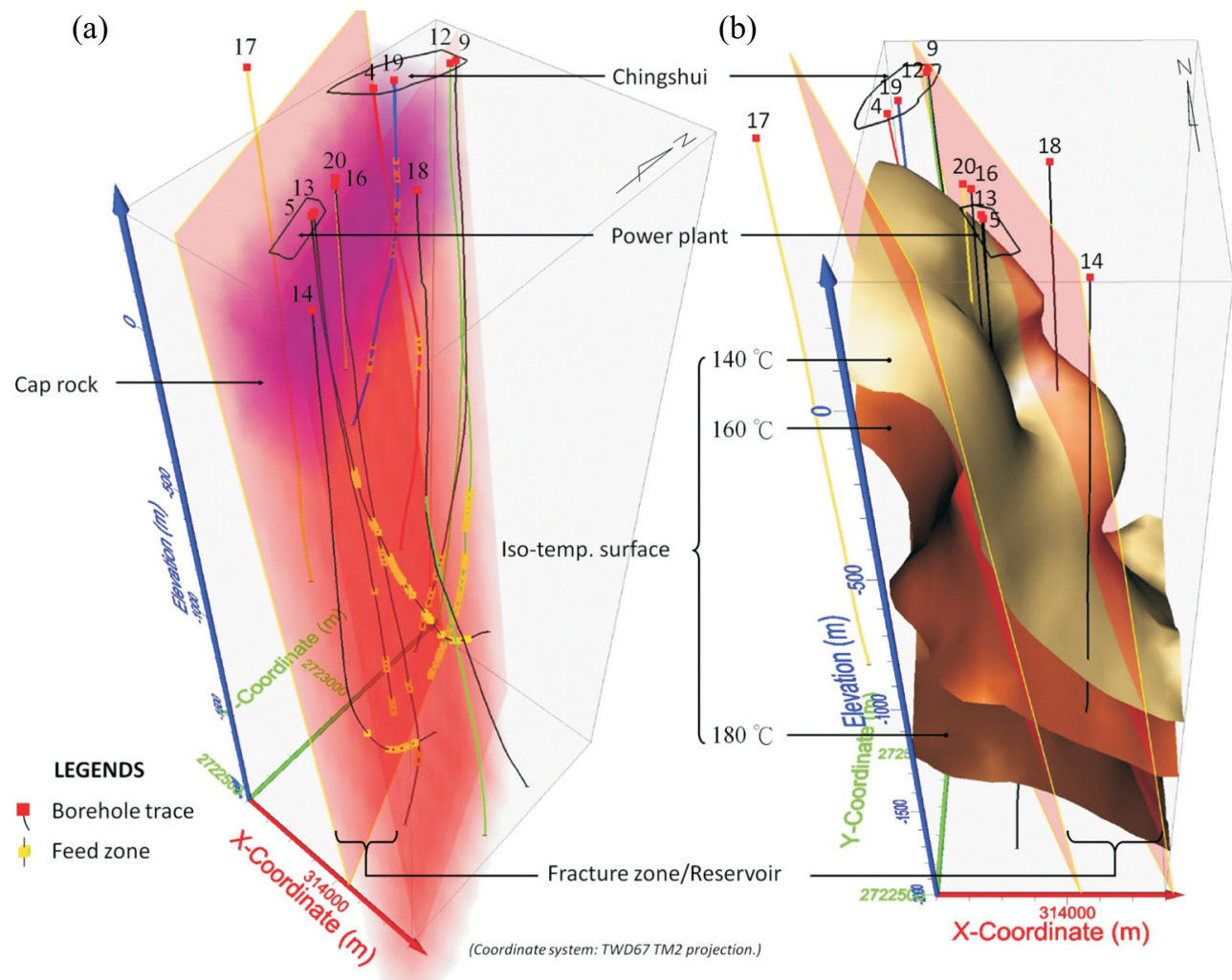

Fig. 12. 3-D geothermal conceptual model of the zoomed-in area of the black dashed box in Fig. 9. (a) The reservoir is confined in an area $260 \mathrm{~m}$ in width, $\mathrm{N} 21^{\circ} \mathrm{W}$, and it dips $80^{\circ}$ to the NE. (b) The iso-temperature surface dips steeply toward the east, and high-temperature hot water rises upward in the $\mathrm{SE}$ region of the reservoir. 


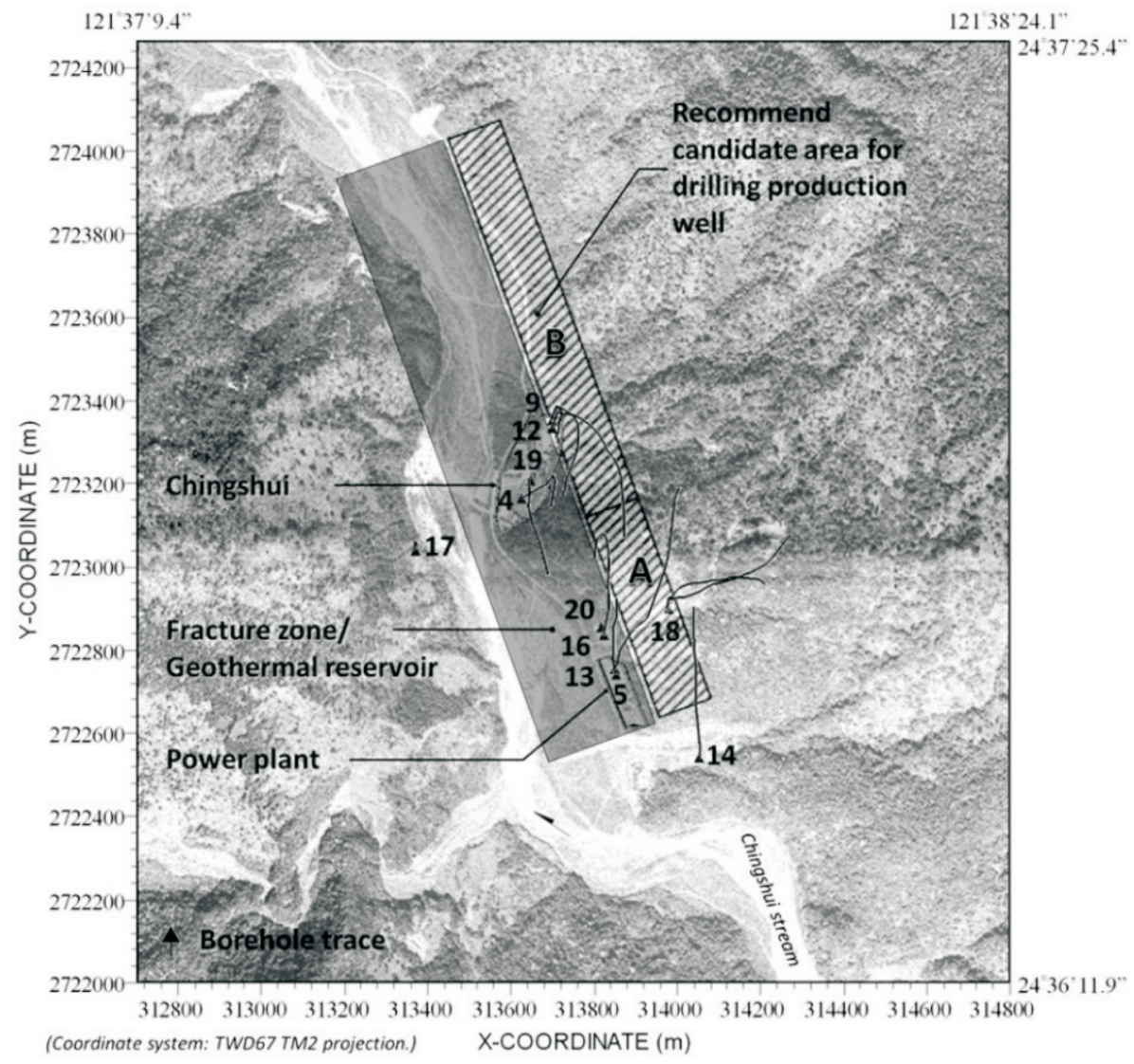

Fig. 13. Surface projection of the borehole traces and the geothermal reservoir. The aerial photo is used as the base map. The shaded areas are the candidate areas for drilling production wells for future geothermal development. Area A is most suitable for drilling production wells, and the recommended depth for this area is $1500 \mathrm{~m}$.

and velocity structure in the Ilan plain by Lin et al. (2004), we propose that intrusive igneous rock might be related to the upper part of the upward cooled magma body, resulting in a WE high magnetic anomaly in the middle of the Ilan plain. The existence of the magma chamber and the intrusive igneous rock results in a high heat flow and geothermal gradient; furthermore, the NE deep fault system within the meta-sandstone provides a meteoric recharge from a higher elevation to artesianally drive the geothermal system. This confirms that the geothermal fluid had circulated deep within the fracture zone and was heated by a deeply located hot body of rock, which is coincident with the ${ }^{3} \mathrm{He} /{ }^{4} \mathrm{He}$ observation of Yang et al. (2005).

The fault system in the Chingshui area was interpreted from geologic, gravity, and magnetotelluric data. The geothermal reservoir might be related to the fracture zone of the Chingshuihsi fault and is bounded by the $\mathrm{C}$-fault in the north and the Xiaonanao fault in the south. In this study, a 3-D geothermal conceptual model was constructed based on the information collected from geophysical interpretations and well logs. The geothermal reservoir is confined within an area $260 \mathrm{~m}$ in width, $\mathrm{N} 21^{\circ} \mathrm{W}$, and it dips $80^{\circ}$ toward NE. The iso-temperature surface steeply dips toward the east, coinciding with the dipping fracture zone of the Chingshuihsi fault. A high-temperature zone is found in the $\mathrm{SE}$ region of the reservoir, which is about $500 \mathrm{~m}$ in length, and lies near the intersection of the Chingshuihsi and Xiaonanao faults, where the temperature of the geothermal fluid can reach $140^{\circ} \mathrm{C}$ and $160^{\circ} \mathrm{C}$ at depths of 200 and $600 \mathrm{~m}$, respectively.

Two areas on the NE side of the geothermal reservoir are recommended for drilling production wells for future geothermal development. It is suggested that the borehole be drilled vertically down to a certain depth and then directed toward the reservoir to penetrate all possible feed zones within the reservoir. Area A, which lies beside the hightemperature zone, is most suitable for drilling production wells, and the recommended depth in this area is $1500 \mathrm{~m}$. On the other hand, the recommended depth in area B should be greater than $2000 \mathrm{~m}$ owing to the greater depth of the reservoir in that area.

Acknowledgements This research benefits from the project for technological development and promotion of geothermal energy study, funded by the Bureau of Energy, Ministry of Economic Affairs, Republic of China. The authors would like to express their thanks to Mr. 
Yan-Tsong Hwang and Mr. Jung-Hui Chen for their efforts in field work.

\section{REFERENCES}

Bertani, R., 2005: World geothermal generation 2001-2005: State of the art. Proceedings World Geothermal Congress 2005, Turkey.

Chen, K. J., C. H. Lin, and C. J. Hsieh, 2002: Mapping seismic attention structures of the volcanic area in northern Taiwan. West. Pac. Earth Sci., 2, 273-290.

Cheng, W. T. and C. F. Lee, 1977: Bipole-dipole resistivity mapping in the Chingshui geothermal area. Mining \& Metallurgy, 21, 2, 88-93.

Chiang, S. C. and Y. F. Liu, 1983: Application of TDEM method in the Chingshui geothermal area, Ilan, Taiwan. Petrol. Geol. Taiwan, 19, 197-218.

Chiang, S. C., J. J. Lin, C. R. Y. Chang, and T. M. Wu, 1979: A preliminary study of the Chingshui geothermal area, Ilan, Taiwan. Proceedings Fifth Geothermal Workshop, Geothermal Reservoir Engineering, Stanford, USA, 249254.

Fridleifsson, I. B., 2001: Geothermal energy for the benefit of the people. Renewable and Sustainable Energy Reviews, $\mathbf{5}$, 299-312.

Hsiao, P. T. and S. C. Chiang, 1979: Geology and geothermal system of the Chingshui-Tuchang geothermal area, Ilan, Taiwan. Petrol. Geol. Taiwan, 16, 205-213.

Hsu, S. K., 2002: Imaging magnetic sources using Euler's equation. Geophys. Prospect., 50, 15-25.

Hsu, S. K., J. C. Sibuet, and C. T. Shyu, 1996: High-resolution detection of geologic boundaries from potential-field anomalies: An enhanced analytic signal technique. Geophysics, 61, 373-386.

Keating, P. B., 1998: Weighted Euler deconvolution of gravity data. Geophysics, 63, 1595-1603.

Lee, C. R., 1994: Compilation of the geothermal prospects data in Taiwan during 1966-1979. Bureau of Energy Report, $500 \mathrm{pp}$.

Lin, C. H., 2000: Thermal modelling of continental subduction and exhumation constrained by heat flow and seismicity in Taiwan. Tectonophysices, 324, 189-201.

Lin, C. H. and Y. H. Yeh, 2001: Three-dimensional P- and $\mathrm{S}$-wave velocity structures of the Chingshui-Tuchang geothermal area in northeastern Taiwan. West. Pac. Earth Sci., 1, 73-84.

Lin, C. W. and W. H. Lin, 1995: Geologic map and explanatory text of Taiwan, Sanshin. Geologic Map of Taiwan, Scale $1: 50000,15$.

Lin, C. W. and C. N. Yang, 1999: Structure styles of the slate and schist belts in northeastern Taiwan. Bull. Cent. Geol. Surv., 12, 39-62.
Lin, J. Y., S. K. Hsu, and J. C. Sibuet, 2004: Melting features along the western Ryukyu slab edge (northeast Taiwan): Topographic evidence. J. Geophys. Res., 109, B12402, doi:10.1029/2004JB003260.

Lund, J. W., D. H. Freeston, and T. L. Boyd, 2005: Direct application of geothermal energy: 2005 Worldwide review. Geothermics, 34, 6, 691-727.

Reid, A. B., J. M. Allsop, H. Granser, A. J. Millett, and I. W. Somerton, 1990: Magnetic interpretation in three dimensions using Euler deconvolution. Geophysics, 55, 80-91.

Rodi, W. and R. L. Mackie, 2001: Nonlinear conjugate gradients algorithm for 2-D magnetotelluric inversion. Geophysics, 66, 174-187.

Roy, L., B. N. P. Agarwal, and R. K. Shaw, 2000: A new concept in Euler deconvolution of isolated gravity anomalies. Geophys. Prospect., 48, 3, 559-575.

Salem, A. and D. Ravat, 2003: A combined analytic signal and Euler method (AN-EUL) for automatic interpretation of magnetic data. Geophysics, 68, 1952-1961.

Su, F. C., 1978: Resistivity survey in the Chingshui prospect, Ilan, Taiwan. Petrol. Geol. Taiwan, 16, 255-264.

Tong, L. T. and T. R. Guo, 2007: Gravity terrain effect of the seafloor topography in Taiwan. Terr. Atmos. Ocean. Sci., 18, 699-713.

Tseng, C. S., 1978: Geology and geothermal occurrence of the Chingshui and Tuchang districts, Ilan. Petrol. Geol. Taiwan, 15, 11-23.

Uchida, T., Y. Song, T. J. Lee, Y. Mitsuhata, S. K. Lim, and S. K. Lee, 2005: Magnetotelluric survey in an extremely noisy environment at the Pohang low-enthalpy geothermal area, Korea. Proceedings World Geothermal Congress 2005, Turkey.

Ushijima, K., J. M. Enjang, J. Hisashi, and M. Hideki, 2005: Magnetotelluric soundings in the Takigami geothermal area, Japan. Proceedings World Geothermal Congress 2005, Turkey.

Wannamaker, P. E., P. E. Rose, W. M. Doerner, J. McCulloch, and K. Nurse, 2005: Magnetotelluric surveying and monitoring at the Coso geothermal area, California, in support of the enhanced geothermal systems concept: Survey Parameters, Initial Results. Proceedings World Geothermal Congress 2005, Turkey.

Yang, T. F., T. F. Lan, H. F. Lee, C. C. Fu, P. C. Chuang, C. H. Lo, C. H. Chen, C. T. A. Chen, and C. S. Lee, 2005: Gas compositions and helium isotopic ratios of fluid samples around Kuishantao, NE offshore Taiwan and its tectonic implications. Geochem. J., 39, 469-480.

Yui, T. F., K. K. Liu, and Y. N. Shieh, 1993: Stable isotope systematics of argillite/slate from a deep well in the Chingshui geothermal field, Taiwan. Chem. Geol., 103, 181-191.

Yu, S. B. and Y. B. Tsai, 1979: Geomagnetic anomalies of the Ilan plain, Taiwan. Petrol. Geol. Taiwan, 16, 19-27. 